\title{
TGF-ק1-Induced Epithelial-to-Mesenchymal Transition and Therapeutic Intervention in Diabetic Nephropathy
}

\author{
Claire E. Hills Paul E. Squires \\ Department of Biological Sciences, The University of Warwick, Coventry, UK
}

\section{Key Words}

Transforming growth factor- $\beta \cdot$ Epithelial-to-mesenchymal transition - Diabetic nephropathy

\begin{abstract}
Background/Aims: Epithelial-to-mesenchymal cell transformation (EMT) is the trans-differentiation of tubular epithelial cells into myofibroblasts, an event underlying progressive chronic kidney disease in diabetes, resulting in fibrosis. Mainly reported in proximal regions of the kidney, EMT is now recognized as a key contributor to the loss of renal function throughout the nephron in diabetic nephropathy (DN). Concomitant upregulation of TGF- $\beta$ in diabetes makes this pro-fibrotic cytokine an obvious candidate in the development of these fibrotic complications. This article reviews recent findings clarifying our understanding of the role of TGF- $\beta$ and associated sub-cellular proteins in EMT. Methods: To understand the pathology of EMT and the role of TGF- $\beta$, we reviewed the literature using PubMed for English language articles that contained key words related to EMT, TGF$\beta$ and DN. Results: EMT and phenotypic plasticity of epithelial cells throughout the nephron involves cytoskeletal reorganization and de novo acquisition of classic mesenchymal markers. Concurrent downregulation of epithelial adhesion molecules results in a loss of function and decreased cell coupling, contributing to a loss of epithelial integrity. TGF- $\beta 1$
\end{abstract}

is pivotal in mediating these phenotypic changes. Conclusion: TGF- $\beta$-induced EMT is a key contributor to fibrotic scar formation as seen in $\mathrm{DN}$, and novel routes for future therapeutic intervention are discussed.

Copyright $\odot 2009$ S. Karger AG, Basel

\section{Introduction}

Diabetic nephropathy (DN) is the single commonest cause of entry into the renal replacement therapy programme and the leading cause of end-stage renal failure in diabetes mellitus [1]. DN refers to a set of structural and functional changes which arise in response to chronic glycaemic assault [2]. Structural abnormalities include hypertrophy, glomerular basement membrane thickening, tubular atrophy and interstitial fibrosis [3]. These changes contribute to increased glomerular filtration rate, proteinuria, systemic hypertension and loss of renal function [3]. Histologically, DN is characterised by an accumulation of extracellular matrix (ECM) proteins in both the glomerular mesangium and tubular interstitium culmi-

This is a contribution from the Warwickshire Institute for Diabetes, Endocrinology and Metabolism Centre. C.E.H. is a recipient of a Wellcome Trust 'Value in People' award.

\section{KARGER}

Fax +41613061234

E-Mail karger@karger.ch

www.karger.com (c) 2009 S. Karger AG, Basel

0250-8095/10/0311-0068\$26.00/0

Accessible online at:

www.karger.com/ajn
Dr. Paul E. Squires

Department of Biological Sciences

The University of Warwick

Coventry CV4 7AL (UK)

Tel. +44 247672 976, E-Mail p.e.squires@warwick.ac.uk 
nating in a decline in excretory function and excessive renal scarring [3, 4]. Renal fibrosis manifests itself as glomerulosclerosis, tubulointerstitial fibrosis, infiltration of inflammatory mediators and the activation of $\alpha$-smooth muscle actin ( $\alpha$-SMA)-positive myofibroblasts. Tubular epithelial-to-mesenchymal transition (EMT), or the transdifferentiation of tubular epithelial cells into myofibroblasts, mediates excessive deposition of the ECM. This ability to switch phenotype stems from a unique plasticity of epithelial cells and is implicated in the generation of interstitial fibroblasts in the diseased kidney. EMT of proximal tubule cells (PTC) has been clearly documented in $\mathrm{DN}$, and overwhelming evidence implicates TGF- $\beta 1$ as the predominant agent mediating these fibrotic changes. This review discusses our current knowledge of TGF- $\beta 1$ induced EMT in DN in both the PTC and collecting duct of the kidney. Finally, we discuss potential therapeutic strategies to inhibit renal fibrogenesis in diabetes.

\section{EMT in the Kidney}

Developmentally, renal tubules are derived from the metanephric mesenchyme through a process termed mesenchymal-to-epithelial transdifferentiation (MET). This cellular differentiation is not static and cells retain the ability to revert back to their original mesenchymal phenotype through EMT. Commonly associated with epithelia of embryonic origin, this plasticity is critical in early stages of development. In adults, EMT is associated with tissue injury and repair; a process instigated as the demand for fibroblasts and wound healing increases [5].

In EMT, the loss of epithelial characteristics coincides with the acquisition of proteins associated with a mesenchymal phenotype. These morphological and phenotypic changes occur at four different stages: (a) the loss of epithelial cell adhesion molecules such as epithelial (E)cadherin and zonula occludens protein $\mathrm{ZO}-1$ are replaced by the (b) mesenchymal markers $\alpha$-SMA and the intermediate filament protein vimentin. The loss of cell adhesion is accompanied by (c) cytoskeletal remodelling and morphological changes resulting in tubular basement membrane (TBM) disruption. (d) Consequently, these cells possess the ability to migrate from the TBM into the interstitium. This migratory capacity leads to increased deposition of the ECM and renders EMT key in the pathology of tubulointerstitial fibrosis. Normally, tubular epithelial cells form a highly coupled epithelial sheet held together by E-cadherin. Loss of E-cadherin expression occurs in the early stages of EMT and results in the dis- sociation of cells within the epithelial sheet [6]. This represents the beginning of a series of events culminating in transition from an epithelial-to-mesenchymal phenotype. Changes in E-cadherin are rapidly accompanied by an upregulation of mesenchymal markers. Reorganization of the actin cytoskeleton into stress fibres containing de novo expressed $\alpha$-SMA is accompanied by an exchange of cytokeratin for vimentin filaments and the expression of fibroblast-specific protein 1 , a Ca ${ }^{2+}$-binding protein involved in motility, invasion, and tubulin polymerization. These morphological and phenotypic changes support matrix remodelling and the migration across the TBM into the interstitial environment where these cells further exacerbate fibrosis [7].

The migratory phenotype used to define EMT remains controversial, especially in the context of fibrosis [8]. Loss of an epithelial phenotype can be clearly identified by a loss in the expression of specific epithelial proteins, in particular E-cadherin. Acquisition of a mesenchymal phenotype is more difficult to attribute [9] and may explain why EMT is often overlooked in studies of renal disease. Markers classically used to define EMT include vimentin and $\alpha$-SMA [10]. However, vimentin is not specific for fibroblastoid cells [11], whilst $\alpha$-SMA, the most commonly used marker in EMT, exhibits heterogeneity of expression [12]. Clarification of EMT in fibrosis is dependent on the identification of a complex interplay of both phenotypic and morphological changes.

\section{The Pathology of EMT}

A role for EMT in the progression of chronic kidney disease was first demonstrated by Iwano et al. [13] in a model of unilateral ureteral obstruction, where $36 \%$ of the matrix-producing cells resident within the tubulointerstitial space were found to be of epithelial origin and derived from renal tubular epithelium through EMT. The underlying pathology of EMT has since been observed in human renal biopsies from diseased kidney, a feature confirmed by the presence of myofibroblasts in which the proportion of cells undergoing EMT was found to correlate with both the level of serum creatinine and the degree of interstitial fibrosis $[14,15]$. In models of renal disease, EMT occurs in response to hypoxia, reactive oxygen species, advanced glycation end products and numerous pro-fibrotic cytokines, growth factors and metalloproteinases [16]. Of these, the pro-fibrotic cytokine TGF- $\beta 1$ is a likely candidate in the development and progression of fibrotic complications observed in DN [17]. 


\section{EMT and the Pathogenesis of Fibrosis in DN}

In diabetes, glomerular fibrosis is observed in the early progression from incipient to overt nephropathy [18]. Whilst tubulointerstitial fibrosis can also present itself in these early stages, a build up of fibrotic material in the tubular interstitium tends to accompany disease progression, correlating with a gradual decline in renal function [19]. Although the origin of fibroblasts in DN remains less clear, progressive renal fibrosis may, in part, be mediated by the phenotypic changes induced by EMT. Analysis of renal histology in both diabetic animals and from the kidneys of patients with DN, confirms the existence of EMT-induced changes. Markers of EMT have recently been observed in streptozotocin (STZ)-treated Wistar Kyoto rats, Sprague-Dawley rats and the STZ Ren-2 rat $[20,21]$. These studies suggest that EMT is closely correlated with a decline in renal function [15]. Recent studies by Yamaguchi et al. [22] have suggested that the existence of fibroblast-specific protein 1 in podocytes from patients with diabetes is most likely to be associated with induction of podocyte detachment through EMT, a potential catastrophic event since the depletion of glomerular podocytes is an important feature of progressive DN.

\section{A Role for TGF- $\beta 1$, Smads and EMT in DN}

A broad-spectrum cytokine, TGF- $\beta$ regulates many biological processes $[23,24]$. Of its three isoforms (TGF$\beta 1,-\beta 2$ and $-\beta 3)$, TGF- $\beta 1$ is the principal mediator of diabetic complications and is key in the development of hypertrophy and the accumulation of ECM $[25,26]$. In models of renal disease and diabetes, TGF- $\beta 1$ gene expression and secretion are increased $[27,28]$, an upregulation that is, in part, due to elevated glucose, advanced glycation end products, PKC and the MAPK pathway [29-32]. However, despite extensive data demonstrating TGF- $\beta$-induced fibrosis, the underlying events mediating the development of the fibrotic lesion are poorly understood. In diabetes, TGF- $\beta 1$ contributes to excessive deposition of fibrotic material through EMT, modulating the expression of several epithelial cell recognition and organizational proteins, including the cadherins, catenins as well as the actin cytoskeleton [33]. In human mesangial cells, TGF- $\beta 1$ induces $\alpha$-SMA, collagen type I expression and cell hypertrophy [34]. Furthermore, the downregulation of E-cadherin expression with the concomitant upregulation of $\alpha$-SMA in tubular epithelial cells strongly supports the case for TGF- $\beta 1$ as a potent stimulus of EMT [35].
Predominantly mediated via Smad-dependent pathways, TGF- $\beta 1$ binds to a distinct receptor, TGF- $\beta$ receptor II (T $\beta$ RII), that activates the TGF- $\beta$ receptor type I (TßRI)-kinase. This association results in the downstream phosphorylation of the Smad proteins. Smads are subdivided into three classes: receptor-regulated Smads (R-Smads; Smad1-3, 5 and 8), the common Smads (Smad4) and the inhibitory Smads (Smad6 and 7). Following TßRII activation, R-Smads form oligomeric complexes with the common Smad prior to translocation and regulation of gene transcription [36]. Transfected cells with a mutant T $\beta R I$ fail to exhibit TGF- $\beta 1$-induced EMT in the absence of Smad activation, despite exhibiting full kinase activity [37]. The majority of TGF- $\beta$-targeted genes regulated in EMT appear to be reliant on Smad3dependent transcriptional regulation [38], though a role for Smad2 should not be discounted [39]. Differential roles for both Smad2 and Smad3 have been identified [40], and a Smad3-dependent reduction of E-cadherin in human proximal tubular cells is paralleled by a Smad2dependent induction of metallomatrix proteinase 2 [41]. Microarray analysis of TGF- $\beta 1$-induced EMT in mouse and human epithelial cells demonstrates a critical requirement for Smad signalling in the regulation of all tested target genes [42]. Smad signalling is stringently controlled in order to protect the cells from an unwanted TGF- $\beta$ response, and a safeguard mechanism exits in the form of both inhibitory Smads and transcriptional co-repressors [43]. The inhibitory Smads (Smad6 and Smad7) inhibit R-Smad phosphorylation by blocking their access to T $\beta \mathrm{RI}$, and/or by promoting the degradation of the receptor complexes. Co-repressors SnoN (Ski-related novel gene, non Alu-containing), Ski (Sloan-Kettering Institute proto-oncogene), and TGIF (TG-interacting factor) prevent gene transcription through inhibition of R-Smads [43]. These antagonists are critical in ensuring the regulation of Smad-mediated gene transcription; therefore, a fine balance must be achieved in order to match the demands of the cell. It is no surprise that diminished levels of co-repressors SnoN, Ski and TGIF are observed in animal models of obstructive nephropathy and diabetes [44]. Smad ubiquitination regulatory factor-2 (Smurf2) is an ubiquitin ligase that specifically targets certain members of Smad proteins for degradation, including Ski, SnoN and TGIF [45]. The close association between Smurf2 expression and enhanced SnoN degradation [44] suggests that the dysregulation of Smurf2 is most likely to affect profibrotic TGF- $\beta /$ Smad signalling and may contribute to the development and progression of human kidney fibrotic diseases [45]. 


\section{TGF- $\beta$, Serum- and Glucocorticoid-Inducible Kinase-1 and EMT in the Collecting Duct}

The role of TGF- $\beta$ in more distal regions of the nephron is yet to be established. In the collecting duct, TGF- $\beta$ promotes increased expression of the serum- and glucocorticoid-inducible kinase-1 (SGK1), a serine/threonine kinase that regulates sodium re-absorption through control of the epithelial sodium channel [46]. SGK1 is elevated in models of diabetes [47], suggesting that it may contribute to the development of secondary hypertension. Interestingly, SGK1 is expressed in numerous tissues that exhibit fibrosis including cases of Crohn's disease, lung fibrosis, liver cirrhosis, fibrosing pancreatitis, DN and glomerulonephritis [48]. These studies suggest that SGK1 may mediate some TGF- $\beta$-induced fibrotic effects. In diabetic mice, SGK1 potentiates the effect of high glucose on fibronectin formation [49], a response that in human fibroblasts has been found to be dependent on the epidermal growth factor receptor [50]. EMT has been confirmed in the collecting duct in a model of fetal unilateral ureteral obstruction [51] and both insulin growth factor 1 and TGF- $\beta 1$ have been shown to induce classic EMT-like changes in mouse inner medullary collecting duct cells [52], despite initial studies suggesting that these cells could not undergo phenotypic conversion in response to TGF- $\beta 1$ [53]. How TGF- $\beta 1$-induced EMT contributes to fibrosis in the distal nephron is unclear. In 2009, Aldehni et al. [54] demonstrated that TGF- $\beta 1$-induced EMT in mouse renal collecting ducts increased levels of Bestrophin 1 (Best1), a compound which controls intracellular $\mathrm{Ca}^{2+}$ concentration and increases cellular proliferation. Suppression of Best1 by RNAi inhibited proliferation and downregulated markers of EMT, suggesting that Best1 may function as a downstream mediator of TGF- $\beta 1$-induced EMT and renal fibrosis in the collecting duct.

\section{Therapeutic Intervention}

Although TGF- $\beta 1$ is regarded as the major isoform involved in fibrosis, improved renal function coincides with reduced expression of both TGF- $\beta 1$ and $-\beta 2$ [55]. Furthermore, a pro-fibrotic role for all three isoforms has been observed in diabetes [56]. The pro-fibrotic actions of TGF- $\beta$ make it an ideal therapeutic target for renoprotective agents. Neutralizing TGF- $\beta 1$, TGF- $\beta 2$ or TGF- $\beta 3$ reduces renal scarring and diminishes a loss of kidney function $[57,58]$. Inhibition of TGF- $\beta$ in this way also prevents glomerular enlargement and suppresses the ex- pression of genes encoding for the ECM in models of chemically induced diabetes [57]. These findings were corroborated in $d b / d b$ mice, where both TGF- $\beta$ and TGF$\beta R$ mRNA expression were increased [58]. Chronic treatment of these animals with TGF- $\beta$-neutralizing antibodies markedly diminished the expression of collagen and fibronectin and reduced mesangial matrix expansion. Several anti-fibrotic and renoprotective agents have been shown to partially alleviate TGF- $\beta$ induced fibrosis and include bone morphogenic protein 7 (BMP-7) and hepatocyte growth factor (HGF).

Identified as an osteogenic factor, BMP-7 plays an important role in kidney development and the regulation of nephrogenesis associated with MET. Renal fibrosis in diabetes is inhibited by BMP-7. Following EMT, increased levels of TGF- $\beta$ are paralleled by a reduction in expression of BMP-7, as a potential consequence of increased gremlin levels [59]. Gremlin limits BMP-7 availability and is markedly elevated in humans with $\mathrm{DN}$ [60]. This reciprocal relationship accounts for low BMP-7 concentrations in models of acute and chronic renal injury [61], and explains how exogenous BMP-7 restores renal function through blockade of EMT [62]. Aside from the glomerular renoprotective effects observed in both STZ rats and $d b / d b$ mice, BMP-7 is capable of intercepting at the level of TGF- $\beta$ signalling. In the adult, BMP-7 alleviates TGF- $\beta$-induced renal fibrosis [63] and antagonises TGF$\beta$-induced Smad3-dependent EMT [64]. However, the mechanism remains elusive since BMP-7 is unable to negate TGF- $\beta$-induced EMT in human PTC, suggesting that the effects of BMP-7 are region specific [65]. The extent to which BMP-7 blocks EMT requires further clarification.

A key anti-fibrotic cytokine, HGF prevents renal tissue fibrosis after chronic injury [66]. Administration of HGF reduces loss of kidney function, whilst blockade of HGF signalling further exacerbates the extent and progression of renal fibrosis [67]. As with BMP-7, HGF and TGF- $\beta$ have a reciprocal relationship. HGF inhibits TGF$\beta$-induced EMT, and ameliorates renal fibrotic lesions in numerous renal disease models [67]. The underlying molecular mechanisms mediating these renoprotective effects are unknown. The anti-fibrotic activity of HGF appears to stem from upregulation of the transcriptional co-repressor SnoN. Binding of this co-repressor to Smad2 results in formation of a transcriptionally inactive complex, preventing the activation of Smad-mediated genes, thereby blocking TGF- $\beta$-induced EMT [68]. Administration of HGF has been shown to alleviate renal complications in $\mathrm{DN}$, including the reversal of glomerulosclero- 
sis [69], a reduction in albuminuria [70] and blockade of fibrosis with a concomitant improvement in renal function [71]. However, a number of studies contradict these findings, suggesting that chronically elevated HGF promotes the progression of nephropathy in $d b / d b$ mice [72]. Furthermore, potential proto-oncogenic actions of HGF raise questions as to the potential therapeutic use of this growth factor in alleviating EMT-induced complications in DN. Further studies are essential if HGF is to be considered as a future therapeutic intervention for fibrosis in DN.

EMT is a complex process involving numerous downstream signalling cascades. Strategies to disrupt any one of these may negate EMT and prevent fibrosis. Identifying other renoprotective agents may unearth future therapeutic interventions. Potential candidates recently identified upstream of HGF include 9-cis retinoic acid, 1,25dihydroxyvitamin $\mathrm{D}_{3}$, the PPAR $\gamma$ agonist troglitazone and C-peptide [33, 69-71]. A cleavage product of pro-insulin, C-peptide exerts a number of protective effects against the microvascular and macrovascular complications associated with hyperglycaemia [72] and in patients with DN, C-peptide is renoprotective [73]. Furthermore, C-peptide has been shown to negate TGF- $\beta$-induced EMT in cells of the proximal tubule [33]. As an adjunct to insulin therapy, C-peptide could be used to alleviate some renal complications of diabetes. However, like BMP-7 and HGF these findings are preliminary and whilst encouraging, need to be fully corroborated in the clinical scenario.

\section{Conclusion}

TGF- $\beta$-induced EMT is a key contributor to fibrotic scar formation as seen in DN. Manipulating downstream TGF- $\beta$ signalling represents a viable therapeutic target to alleviate fibrosis and restore renal function. Administration of the anti-fibrotic growth factors HGF or BMP-7 can reverse the fibrogenic response, and growing evidence supports the use of novel renoprotective agents to assist in alleviating complications of chronic kidney disease, including DN.

\section{References}

1 US Renal Data System: USRDS (2003) Annual Data Report: Atlas of End-Stage Renal Disease in the United States. Bethesda, National Institute of Health, 2003.

$\checkmark 2$ Soldatos G, Cooper ME: DN: Important pathophysiologic mechanisms. Diabetes Res Clin Pract 2008;82:1:S75-S79.

-3 Mauer SM, Steffes MW, Ellis EN, Sutherland DE, Brown DM, Goetz FC: Structural functional relationships in DN. J Clin Invest 1984;74:1143-1155.

-4 Steffes MW, Osterby R, Chavers B, Mauer SM: Mesangial expansion as a central mechanism for loss of kidney function in diabetic patients. Diabetes 1989;38:1077-1081.

$\checkmark 5$ Greenburg G, Hay ED: Epithelia suspended in collagen gels can lose polarity and express characteristics of migrating mesenchymal cells. J Cell Biol 1982;95:333-339.

-6 Zheng G, Lyons JG, Tan TK, Wang Y, Hsu TT, Min D, Succar L, Rangan GK, Hu M, Henderson BR, Alexander SI, Harris DC: Disruption of E-cadherin by matrix metalloproteinase directly mediates epithelialmesenchymal transition downstream of transforming growth factor-betal in renal tubular epithelial cells. Am J Pathol 2009; 175:580-591.
7 Zeisberg M, Kalluri R: The role of epithelialto-mesenchymal transition in renal fibrosis. J Mol Med 2004;82:175-181.

-8 Nawshad A, Lagamba D, Polad A, Hay ED: Transforming growth factor-beta signaling during epithelial-mesenchymal transformation: implications for embryogenesis and tumor metastasis. CTO 2005;179:11-23.

-9 Zavadil J, Böttinger EP: TGF-beta and epithelial-to-mesenchymal transitions. Oncogene 2005;24:5764-5774.

10 Lee JM, Dedhar S, Kalluri R, Thompson EW: The epithelial-mesenchymal transition: new insights in signaling, development, and disease. J Cell Biol 2006;172:973-981.

$\checkmark 11$ Okada H, Ban S, Nagao S, Takahashi H, Suzuki H, Neilson EG: Progressive renal fibrosis in murine polycystic kidney disease: an immunohistochemical observation. Kidney Int 2000;58:587-597.

12 Badid C, Desmouliere A, Babici D, Hadj-Aissa A, McGregor B, Lefrancois N, Touraine JL, Laville M: Interstitial expression of alpha-SMA: an early marker of chronic renal allograft dysfunction. Nephrol Dial Transplant 2002;17:1993-1998.

13 Iwano M, Plieth D, Danoff TM, Xue C, Okada H, Neilson EG: Evidence that fibroblasts derive from epithelium during tissue fibrosis. J Clin Invest 2002;110:341-350.
14 Ng YY, Huang TP, Yang WC, Chen ZP, Yang $\mathrm{AH}, \mathrm{Mu}$ W, Nikolic-Paterson DJ, Atkins RC, Lan HY: Tubular epithelial-myofibroblast transdifferentiation in progressive tubulointerstitial fibrosis in 5/6 nephrectomized rats. Kidney Int 1998;54:864-876.

15 Rastaldi MP, Ferrario F, Giardino L, Dell'Antonio G, Grillo C, Grillo P, Strutz F, Müller GA, Colasanti G, D’Amico G: Epithelial-mesenchymal transition of tubular epithelial cells in human renal biopsies. Kidney Int 2002;62:137-146.

16 Burns WC, Twigg SM, Forbes JM, Pete J, Tikellis C, Thallas-Bonke V, Thomas MC, Cooper ME, Kantharidis P: Connective tissue growth factor plays an important role in advanced glycation end product-induced tubular epithelial-to-mesenchymal transition: implications for diabetic renal disease. J Am Soc Nephrol 2006;17:2484-2494.

17 Willis BC, Liebler JM, Luby-Phelps K, Nicholson AG, Crandall ED, du Bois RM, Borok $\mathrm{Z}$ : Induction of epithelial-mesenchymal transition in alveolar epithelial cells by transforming growth factor-beta1: potential role in idiopathic pulmonary fibrosis. Am J Pathol 2005;166:1321-1332. 
18 Mason RM, Wahab NA: Extracellular matrix metabolism in diabetic nephropathy. J Am Soc Nephrol 2003;14:1358-1373.

19 Katz A, Caramori ML, Sisson-Ross S, Groppoli T, Basgen JM, Mauer M: An increase in the cell component of the cortical interstitium antedates interstitial fibrosis in type 1 diabetic patients. Kidney Int 2002;61:20582066.

20 Li Y, Yang J, Dai C, Wu C, Liu Y: Role for integrin-linked kinase in mediating tubular epithelial to mesenchymal transition and renal interstitial fibrogenesis. J Clin Invest 2003;112:503-516.

-21 Holian J, Qi W, Kelly DJ, Zhang Y, Mreich E, Pollock CA, Chen XM: Role of Kruppel-like factor 6 in transforming growth factorbeta1-induced epithelial-mesenchymal transition of proximal tubule cells. Am J Physiol Renal Physiol 2008;295:F1388-F1396.

-22 Yamaguchi Y, Iwano M, Suzuki D, Nakatani K, Kimura K, Harada K, Kubo A, Akai Y, Toyoda M, Kanauchi M, Neilson EG, Saito Y: Epithelial-mesenchymal transition as a potential explanation for podocyte depletion in diabetic nephropathy. Am J Kidney Dis 2009;54:653-664.

23 Hills CE, Bland R, Bennett J, Ronco PM, Squires PE: TGF-betal mediates glucoseevoked up-regulation of connexin-43 cellto-cell communication in HCD-cells. Cell Physiol Biochem 2009;24:177-186.

-24 Bottinger EP, Bitzer M: TGF-beta signaling in renal disease. J Am Soc Nephrol 2002;13: 2600-2610.

25 Dan DC, Hoffman BB, Hong SW: Therapy with antisense TGF-D $\beta 1$ oligodeoxynucleotides reduces kidney weight and matrix mRNAs in diabetic mice. Am J Physiol Renal Physiol 2000;278:F628-F634.

26 Ziyadeh FN: The extracellular matrix in DN. Am J Kidney Dis 1992;22:36-44.

$\checkmark 27$ Yamamoto T, Nakamura T, Noble NA, Ruoslahati E, Border WA: Expression of transforming growth factor beta is elevated in human and experimental DN. Proc Natl Acad Sci 1993;90:1814-1818.

28 Sharma K, Ziyadeh FN, Alzahabi B, McGowan TA, Kapoor S, Kurnik BR, Kurnik $\mathrm{PB}$, Weisberg LS: Increased renal production of transforming growth factor-beta 1 in patients with type II diabetes. Diabetes 1997; 46:854-859.

29 Hills CE, Bland R, Bennett J, Ronco PM, Squires PE: High Glucose up-regulates ENaC and SGK1 expression in HCD-cells. Cell Physiol Biochem 2006;18:337-346.

30 Fukami K, Ueda S, Yamagishi S, Kato S, Inagaki Y, Takeuchi M, Motomiya Y, Bucala R, Iida S, Tamaki K, Imaizumi T, Cooper ME, Okuda S: AGEs activate mesangial TGFbeta-Smad signaling via an angiotensin II type I receptor interaction. Kidney Int 2004; 66:2137-2147.
31 Wu D, Peng F, Zhang B, Ingram AJ, Kelly DJ, Gilbert RE, Gao B, Krepinsky JC: PKC-beta1 mediates glucose-induced Akt activation and TGF-beta1 upregulation in mesangial cells. J Am Soc Nephrol 2009;20:554-566.

32 Fujita H, Omori S, Ishikura K, Hida M, Awazu M: ERK and p38 mediate high-glucoseinduced hypertrophy and TGF- $\beta$ expression in renal tubular cells. Am J Physiol Renal Physiol 2004;286:F120-F126.

33 Hills CE, Al-Rasheed N, Al-Rasheed N, Willars GB, Brunskill NJ: C-peptide reverses TGF-beta-1 induced changes in renal proximal tubular cells: implications for treatment of DN. Am J Physiol 2009;296:F614-F621.

34 Dai C, Liu Y: Hepatocyte growth factor antagonizes the profibrotic action of TGF- $\beta 1$ in mesangial cells by stabilizing Smad transcriptional corepressor TGIF. J Am Soc Nephrol 2004;15:1402-1412.

35 Yang J, Liu Y: Dissection of key events in tubular epithelial to myofibroblast transition and its implications in renal interstitial fibrosis. Am J Pathol 2001;159:1465-1475.

-36 Dennler S, Itoh S, Vivien D, Dijke P, Huet S, Gauthier J: Direct binding of smad 3 and smad4 to critical TGF- $\beta$ inducible elements in the promoter of the human plasminogen activator inhibitor-type 1 gene. ЕMBO J 1998;17:3091-3100.

- 37 Itoh S, Thorikay M, Kowanetz M, Moustakas A, Itoh F, Heldin CH, ten Dijke P: Elucidation of Smad requirement in transforming growth factor-beta type I receptor-induced responses. J Biol Chem 2003;278:3751-3761.

38 Sato M, Muragaki Y, Saika S, Roberts AB, Ooshima A: Targeted disruption of TGFbeta1/Smad3 signaling protects against renal tubulointerstitial fibrosis induced by unilateral ureteral obstruction. J Clin Invest 2003;112:1486-1494.

-39 Ju W, Ogawa A, Heyer J, Nierhof D, Yu L, Kucherlapati R, Shafritz DA, Bottinger EP: Deletion of Smad2 in mouse liver reveals novel functions in hepatocyte growth and differentiation. Mol Cell Biol 2006;26:654667.

40 Brown KA, Pietenpol JA, Moses HL: A tale of two proteins: differential roles and regulation of Smad2 and Smad3 in TGF-beta signaling. J Cell Biochem 2007;101:9-33.

41 Phanish MK, Wahab NA, Colville-Nash P, Hendry BM and Dockrell ME: The differential role of Smad2 and Smad3 in the regulation of pro-fibrotic TGFbetal responses in human proximal-tubule epithelial cells. Biochem J 2006;15:601-607.

42 Valcourt U, Kowanetz M, Niimi H, Heldin $\mathrm{CH}$, Moustakas A: TGF-beta and the Smad signaling pathway support transcriptomic programming during epithelial-mesenchymal cell transition. Mol Biol Cell 2005;16: 1987-2002.

43 Luo K: Ski and SnoN: negative regulators of TGF-beta signaling. Curr Opin Genet Dev 2004;14:65-70.
44 Fukasawa H, Yamamoto T, Togawa A, Ohashi N, Fujigaki Y, Oda T, Uchida C, Kitagawa K, Hattori T, Suzuki S, Kitagawa M, Hishida A: Ubiquitin-dependent degradation of SnoN and Ski is increased in renal fibrosis induced by obstructive injury. Kidney Int 2006;69: 1733-1740.

45 Tan R, He W, Lin X, Kiss LP, Liu Y: Smad ubiquitination regulatory factor- 2 in the fibrotic kidney: regulation, target specificity, and functional implication. Am J Physiol Renal Physiol 2008;294:F1076-F1083.

46 Hills CE, Squires PE, Bland R: Serum and glucocorticoid regulated kinase and disturbed renal sodium transport in diabetes. J Endocrinol 2008;199:343-349.

47 Kumar JM, Brooks DP, Olson BA, Laping NJ: SGK a putative serine/threonine kinase is differentially expressed in the kidney of diabetic mice and humans. J Am Soc Nephrol 1999;10:2488-2494.

48 Wärntges S, Klingel K, Weigert C, Fillon S, Buck M, Schleicher E, Rodemann HP, Knabbe C, Kandolf R, Lang F: Excessive transcription of the human serum and glucocorticoid dependent kinase hSGK1 in lung fibrosis. Cell Physiol Biochem 2002;12:135-142.

49 Stevens VA, Saad S, Chen XM, Pollock CA: The interdependence of EGF-R and SGK-1 in fibronectin expression in primary kidney cortical fibroblast cells. Cell Biol 2007;39: 1047-1054.

50 Feng Y, Wang Q, Wang Y, Yard B, Lang F: SGK1-mediated fibronectin formation in DN. Cell Physiol Biochem 2005;16:237-244.

51 Butt MJ, Tarantal AF, Jimenez DF, Matsell DG: Collecting duct epithelial-mesenchymal transition in fetal urinary tract obstruction. Kidney Int 2007;72:936-944.

52 Ivanova L, Butt MJ, Matsell DG: Mesenchymal transition in kidney collecting duct epithelial cells. Am J Physiol Renal Physiol 2008;294:F1238-F1248.

53 Yang J, Liu Y: Blockage of tubular epithelial to myofibroblast transition by hepatocyte growth factor prevents renal interstitial fibrosis. J Am Soc Nephrol 2002;13:96-107.

54 Aldehni F, Spitzner M, Martins JR, BarroSoria R, Schreiber R, Kunzelmann K: Bestrophin 1 promotes epithelial-to-mesenchymal transition of renal collecting duct cells. J Am Soc Nephrol 2009;20:1556-1564.

55 De Albuquerque DA, Saxena V, Adams DE, Boivin GP, Brunner HI, Witte DP, Singh RR: An ACE inhibitor reduces Th2 cytokines and TGF-betal and TGF-beta 2 isoforms in murine lupus nephritis. Kidney Int 2004;65: 846-859.

56 Coker RK, Laurent GJ, Shahzeidi S, Lympany PA, du Bois RM, Jeffery PK, McAnulty RJ: Transforming growth factors-beta 1, -beta 2 , and -beta 3 stimulate fibroblast procollagen production in vitro but are differentially expressed during bleomycin-induced lung fibrosis. Am J Pathol 1997;150:981-991. 
57 Sharma K, Jin Y, Guo J, Ziyadeh FN: Neutralization of TGF-beta by anti-TGF-beta antibody attenuates kidney hypertrophy and the enhanced extracellular matrix gene expression in STZ-induced diabetic mice. Diabetes 1996;45:522-530.

-58 Ziyadeh FN, Hoffman BB, Han DC, Iglesiasde la Cruz MC, Hong SW, Isono M, Chen S, McGowan TA, Sharma K: Long term prevention of renal insufficiency. Excess matrix gene expression and glomerular mesangial matrix expression by treatment with monoclonal anti-TGF $\beta$ antibody in $\mathrm{db} / \mathrm{db}$ diabetic mice. Proc Natl Acad Sci USA 2000;97:80158020.

-59 Dolan V, Murphy M, Sadlier D, Lappin D, Doran P, Godson C, Martin F, O’Meara Y, Schmid H, Henger A, Kretzler M, Droguett A, Mezzano S, Brady HR: Expression of gremlin, a bone morphogenetic protein antagonist, in human DN. Am J Kidney Dis 2005;45:1034-1039.

60 McMahon R, Murphy M, Clarkson M, Taal M, Mackenzie HS, Godson C, Martin F, Brady HR: IHG-2, a mesangial cell gene induced by high glucose, is human gremlin. Regulation by extracellular glucose concentration, cyclic mechanical strain, and transforming growth factor-beta1. J Biol Chem 2000;7:9901-9904.
61 Wang SN, Lapage J, Hirschberg R: Loss of tubular bone morphogenetic protein-7 in DN. J Am Soc Nephrol 2001;2:2392-2399.

62 Morrissey J, Hruska K, Guo G, Wang S, Chen Q, Klahr S: Bone morphogenetic protein-7 improves renal fibrosis and accelerates the return of renal function. J Am Soc Nephrol 2002;3:S14-S21.

63 Mitu G, Hirschberg R: Bone morphogenetic protein-7 (BMP7) in chronic kidney disease. Front Biosci 2008;13:4726-4739.

64 Zeisberg M, Shah AA, Kalluri R: Bone morphogenic protein-7 induces mesenchymal to epithelial transition in adult renal fibroblasts and facilitates regeneration of injured kidney. J Biol Chem 2005;280:8094-8100.

65 Dudas PL, Argentieri RL, Farrell FX: BMP-7 fails to attenuate TGF-betal-induced epithelial-to-mesenchymal transition in human proximal tubule epithelial cells. Nephrol Dial Transplant 2009;24:1406-1416.

66 Yang J, Liu Y: Blockage of tubular epithelial to myofibroblast transition by hepatocyte growth factor prevents renal interstitial fi brosis. J Am Soc Nephrol 2002;13:96-107.
67 Yang J, Dai C, Liu Y: Systemic administration of naked plasmid encoding hepatocyte growth factor ameliorates chronic renal fibrosis in mice. Gene Ther 2001;8:14701479.

68 Yang J, Dai C, Liu Y: A novel mechanism by which hepatocyte growth factor blocks tubular epithelial to mesenchymal transition. J Am Soc Nephrol 2005; 16:68-78.

69 Wen X, Li Y, Hu K, Dai C, Liu Y: Hepatocyte growth factor receptor signaling mediates the anti-fibrotic action of 9-cis-retinoic acid in glomerular mesangial cells. Am J Pathol 2005; 167:947-957.

70 Masaki T, Doi S, Arakawa T, Yokoyama Y, Doi T, Kohno N, Yorioka N: PPAR-gamma agonist attenuates renal interstitial fibrosis and inflammation through reduction of TGF-beta. Lab Invest 2009;89:47-58.

71 Tan X, Li Y, Liu Y: Therapeutic role and potential mechanisms of active vitamin $\mathrm{D}$ in renal interstitial fibrosis. J Steroid Biochem Mol Biol 2007;103:491-496.

72 Hills CE, Brunskill NJ: Cellular and physiological effects of C-peptide. Clin Sci 2009; 116:565-574.

$>73$ Hills CE, Brunskill NJ: Intracellular signalling by C-peptide. Exp Diabetes Res 2008; 2008:635158. 